\title{
EDITORIAL
}

\section{A strong start, a promising future}

Protein \& Cell has made a very strong start in its first full year of publication, covering 12 monthly issues with a consistently high standard of content and production.

Thanks to the contributors, editors, editorial board, editorial staff and publishers, both the scientific quality and the production quality of the journal have been outstanding. The quality and consistency of the journal has been recognized by the rapid acceptance for indexing in MEDLINE, which was successfully granted in November 2010 with the help of supporting statements from distinguished scientists, including James Watson, Zhijian Chen, lain D Campbell, and Louise Johnson. We offer our sincerest thanks to them for their help and their confidence in the journal.

Each issue of the journal contains a balanced mix of 3-5 reviews and 3-5 research papers, together with commentaries, news, opinions, and recollections of respected scientists, scientific events, or scientific institutions.

The journal website has been developed and improved to provide the necessary instructions for authors and reviewers, alongside easy access

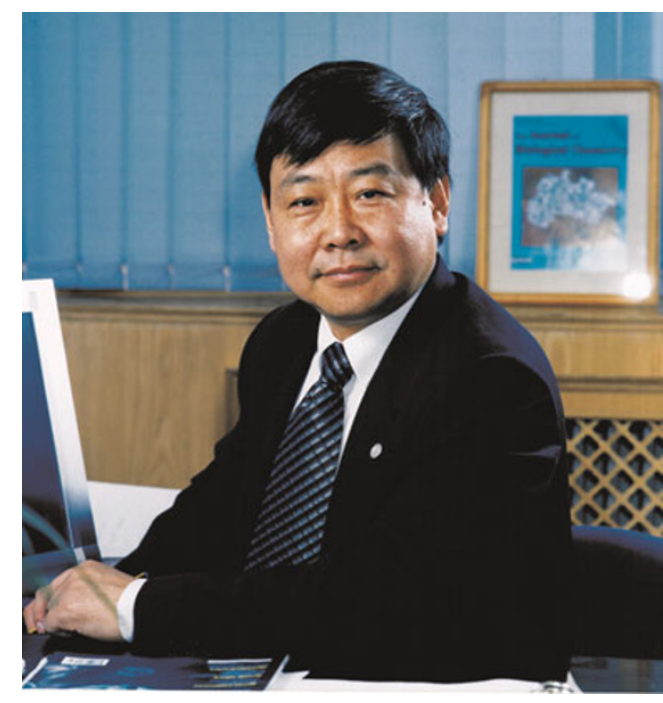
to the journal content, and a number of exceptional papers are highlighted. As noted on the website, the journal currently makes no charge for publication.

The content of Protein \& Cell continues our aims to promote greater understanding of the cell, via structural and functional studies of its components and products. The journal has published reviews and primary papers on a wide range of fascinating topics, from genomics, DNA/RNA structure and functions, nucleosome assembly, DNA replication and repair, protein synthesis, protein structures and activities, signalling phenomena, cell-cell and cell-matrix interactions, through to extracellular phenomena and molecular aspects of development and morphogenesis of multicellular organisms. Our output covers a broad spectrum of traditional specialist areas, with some emphasis on virology (HIV-1, SARS, influenza, enterovirus, HCV, lagovirus, coronavirus, viral integrases, proteases and reverse transcriptases), and also immunology (therapeutic monoclonal antibodies, complement, collectins, immune receptor functions and specificity, antimicrobial peptides and antiviral defence mechanisms). Molecular microbiology, enzymology, genetics, neurosciences, and plant molecular sciences are also represented.

Although the journal is based in China, its international nature has been evident from the first issue. A significant proportion of manuscripts are from scientists in the US (about $27 \%$ of all types of published papers), with others contributed from the UK, Japan, Germany, Singapore, etc. This is consistent with our aim to establish a congregating forum for worldwide scientists in the life sciences.

We have been fortunate to receive many contributions that report novel results and that lie within the mainstream of scientific interest. We look forward to receiving more of the same in the future as the journal becomes more widely known. Again, we call upon our colleagues worldwide to join us in support of Protein \& Cell, and to help build it into an objective, advanced, open and successful journal.

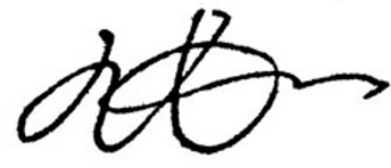

Zihe Rao, PhD

Editor-in-Chief, Protein \& Cell

Beijing, China 